九州大学学術情報リポジトリ

Kyushu University Institutional Repository

\title{
Recombinant Moringa Oleifera Lectin produced in Pichia Pastoris is a Potential Natural Coagulant
}

\section{Muhamad Azhar Abd Wahid}

Department of Environmental Engineering and Green Technology, Malaysia-Japan International Institute of Technology, Universiti Teknologi Malaysia

\section{Megat Johari Megat Mohd Noor}

Department of Environmental Engineering and Green Technology, Malaysia-Japan International Institute of Technology, Universiti Teknologi Malaysia

Hara, Hirofumi

Department of Environmental Engineering and Green Technology, Malaysia-Japan International Institute of Technology, Universiti Teknologi Malaysia

https://doi.org/10.5109/1800867

出版情報: Evergreen. 3 (2)，pp.11-16，2016-09. Green Asia Education Center バージョン：

権利関係 : 


\title{
Recombinant Moringa Oleifera Lectin produced in Pichia Pastoris is a Potential Natural C oagulant
}

\author{
M uhamad Azhar Abd Wahid, Megat Johari M egat Mohd Noor, \\ Hirofumi Hara* \\ Department of Environmental Engineering and Green Technology, \\ Malaysia-Japan International Institute of Technology, Universiti Teknologi M alaysia, \\ Jalan Sultan Y ahya Petra (Jalan Semarak), 54100 Kuala Lumpur, MALAYSIA
}
*A uthor to whom correspondence should be addressed, E-mail: hhara@utm.my

(Received June 24, 2016; accepted September 21, 2016)

\begin{abstract}
The natural coagulant M oringa oleifera lectin ( $\mathrm{M} O \mathrm{~L}$ ) has coagulation efficiency comparable to that of aluminum sulfate and is more environmentally sustainable than the latter. The coagulation efficiencies of culture supernatants from $50 \mathrm{M} \mathrm{oL}$-secreting colonies and a control lacking M oL secretion were compared by observing turbidity removal from a 600 NTU kaolin suspension. Remarkably, $80 \%$ of the tested supernatants showed more than $80 \%$ turbidity removal, down to less than $100 \mathrm{NTU}$, the level achieved with the control supernatant. The coagulation efficiency of the four colonies achieving the highest levels of turbidity removal (colonies 2, 29, 31, and 49) was tested in triplicate alongside a control sample using 200 NTU turbid water. The mean difference in turbidity removal between the four colonies and the control was found to be significant using Dunnett's test $(P<0.01)$. The secreted $\mathrm{M}$ oL from GS115/pPIC9/M oL colony 2 , the most efficient $\mathrm{M}$ oL -producing colony (mean difference compared to control, $42 \% ; \mathrm{P}=0.001$ ), was purified using an $\mathrm{N}$-terminal hexa-His-tag and Ni-NTA spin columns. The expression of MoL was confirmed by the presence of a single $8 \mathrm{kD}$ a band using SDS-PA GE analysis. The recombinant M oL produced by Pichia pastoris was secreted, and possessed a coagulation capacity of $83 \%$, as determined based on the reduction in turbidity of 400 NTU water.
\end{abstract}

Keywords: Lectin, M oringa oleifera, Natural coagulant, Pichia pastoris, Turbidity.

\section{Introduction}

Every year, reports show an increase in human population, urbanization, and industrialization, all of which affect the global demand for clean water ${ }^{1)}$. Although water is present in vast quantities on earth, the total volume that can be directly utilized by humans is only around $0.7 \%{ }^{2)}$. M ore than four billion people live in parts of the world where the scarcity of freshwater directly threatens human water security or river biodiversity.

Traditional water treatment systems generally begin with coagulation, followed by settling or sedimentation, gravity or granular filtration, and finally, chemical disinfection ${ }^{3)}$. The first step in water processing by water treatment plants is usually the removal of colloidal particles through coagulation. The efficiency of this process, and thus the extent of colloidal particle removal, directly affects the final water quality ${ }^{4)}$. The large surface area-to-volume ratio of colloids means that they are naturally resistant to sedimentation under gravity. However, the colloidal surface has a net negative charge, and neutralization of this charge by interactions with particles carrying a net positive charge is a potential strategy for colloid removal. A luminum sulfate (alum) has a charge as high as $4^{+}$in water, although it is more typically bivalent, with a charge of $2^{+}$. A lum is therefore a more effective coagulating, charge-neutralizing particle than a monovalent ion ${ }^{5)}$.

In M alaysia, alum is commonly used as coagulants in water treatment plants. However, studies performed prior to 2001 on the relationship between aluminum in drinking water and A lzheimer's D isease (AD), reveal ed a significant association between aluminum concentrations at or exceeding $100 \mathrm{~g} / \mathrm{L}$ in drinking water and the risk of developing $A D$ 6). Additionally, aluminum is not biodegradable, and therefore the disposal of the sludge that is generated is problematic ${ }^{7)}$.

Throughout the world, various natural coagulants, produced and extracted from plants such as Moringa oleifera, Cactus opuntia, Cactus latifaria, Strychnos potatorum, Prosopis juliflora, Fabaceae, and Jatropha curcas have been utilized in water treatment ${ }^{8)}$. In a previous study, the performance of three natural coagulants, extracted from M. oleifera, S. potatorum, and Phaseolus vulgaris seeds, were compared, and the M. 
oleifera seed extracts were found to be the most effective coagulant ${ }^{9}$. Of all the natural coagulants that have been studied, M. oleifera seed extract is of particular interest, as it possesses both antimicrobial properties and efficient coagulation potential ${ }^{10}$ ). Therefore, lectin, an active compound from $M$. oleifera, has been the focus of recent efforts to replace alum. $M$. oleifera lectin is a cationic protein with a molecular weight of $6.5 \mathrm{kDa}$ and an isoelectric point in the range of 10-11 ${ }^{5}$.

All organisms produce lectins, also known as hemagglutinating protein. In plants, lectin allows seeds to act as sites of deposition. In general, the structure and carbohydrate specificity of lectin in seeds shares no similarity to the lectins found in other plant tissues ${ }^{11)}$.

Instead of obtaining $M$. oleifera seed lectin by conventional means, this study uses a novel recombinant protein engineering approach to sustainably produce the lectin coagulant.

\section{Materials and methods}

The M. oleifera lectin (MoL) gene sequence, represented by the mRNA sequence for $M$. oleifera protein $2.1\left(\mathrm{MO}_{2.1}\right)$, was obtained from the $\mathrm{NCBI}$ database (GenBank: AJ345072.1). The gene sequence was synthesized by Invitrogen, and inserted into the plasmid pPIC9, which was cloned in Escherichia coli $\mathrm{K} 12$ cells.

The pPIC9 plasmid carrying MoL (pPIC9/MoL) was purified and used to transform into $P$. pastoris strain GS115, giving GS115/pPIC9/MoL. The transformation and MoL expression were performed using an EasySelect Pichia Expression Kit according to the manufacturer's instructions ${ }^{12)}$. E. coli/pPIC $9 / \mathrm{MoL}$ was cultured on L uria-B ertani (LB) agar, and Pichia pastoris GS115 was cultured in yeast extract-peptone-dextrose medium (YPD). Following transformation with $\mathrm{pPIC} / \mathrm{MoL}, \mathrm{P}$. pastoris transformants were screened by culturing on selective minimal dextrose (MD) and minimal methanol (MM) agar, simultaneously. MoL expression was induced by culturing GS115/pPIC9/MoL in buffered minimal methanol (BMM) medium.

A nalysis of the coagulation efficiency of the different P. pastoris colonies was performed using a $2100 \mathrm{Q}$ turbidimeter (Hach, USA). A kaolin suspension was used as synthetic turbid water; it was prepared by mixing $10 \mathrm{~g}$ of light kaolin powder ( $R \& M, E s s e x, U K)$ in $1 L$ of ultrapure water, stirring for $1 \mathrm{~h}$, and then incubating at room temperature for $24 \mathrm{~h}$ to complete particle hydration. Turbid waters of 600 NTU and 200 NTU were prepared by diluting the stock solution with ultrapure water to give a final volume of $500 \mathrm{~mL}$.

The 50 colonies of transformed P. pastoris, grown on M M agar, were picked and cultured in BMM medium, and their supernatants were harvested. Colonies were labeled sequentially from GS115/pPIC 9/MoL colony 1 to GS115/pPIC9/MoL colony 50. Next, $10 \mathrm{~mL}$ of supernatant from either $\mathrm{P}$. pastoris GS115/pPIC9/MoL and P. pastoris GS115/his negative control were added to a beaker containing a 600 NTU kaolin suspension.

Jar tests were performed on the supernatants from the 50 cultured colonies, using a PB 900 series programmable jar tester (Phipps and Bird, USA), with 2 min of rapid mixing at $100 \mathrm{rpm}$, followed by $30 \mathrm{~min}$ of slow mixing at $30 \mathrm{rpm}$ and settling for $30 \mathrm{~min}$. The jar testing is shown in Fig. 1.

The four supernatants that gave the highest turbidity removal $(2,29,31$, and 49), along with a control sample, were selected for further investigations into turbidity removal, using a 200 NTU kaolin suspension. The statistical significance of the differences in turbidity removal between the samples and the control was determined using the Dunnett's test at a confidence level of $99 \%(P<0.01)$, using SPSS software.

The MoL gene from GS115/pPIC9/MoL colony 2 was amplified by polymerase chain reaction (PCR), using $\mathrm{M}$ oL-specific

Forward

(5'-CAGGGACCTGGTCGGCAGCC-3') and Reverse (5'-GGTGCTAGGTATATTGGATG-3') primers, to give an amplicon of $224 \mathrm{bp}$. A second confirmation screening with region containing the alcohol dehydrogenase 1 (AOX1) and MoL gene was also amplified using universal AOX 1 forward primer (5'-GACTGGTTCCAATTGACAAGC-3') and AOX 1 reverse primer (5'-GCAAATGGCATTCTGACATCC-3') (Invitrogen).

PCR was carried out in a $20 \mu \mathrm{L}$ reaction mixture, containing $5 \mu \mathrm{L} 5 \times$ reaction buffer, $1.2 \mu \mathrm{L} 25 \mathrm{mM}$ $\mathrm{MgCl}_{2}, 0.4 \mu \mathrm{L} 25 \mathrm{mM}$ dNTPs, $0.4 \mu \mathrm{L}$ forward primer (10 $\rho \mathrm{mol} / \mu \mathrm{L}), 0.4 \mu \mathrm{L}$ reverse primer $(10 \mathrm{\rho mol} / \mu \mathrm{L})$, and $12.5 \mu \mathrm{L}$ P. pastoris cell suspension, added in this order, using a GoTaq ${ }^{\circledR}$ DNA Polymerase kit (Promega Corporation). The PCR was initiated with $0.1 \mu \mathrm{L}$ Taq polymerase, and run for 30 cycles with the following steps: denaturation at $95^{\circ} \mathrm{C}$ for $1 \mathrm{~min}$, annealing at either $51^{\circ} \mathrm{C}$ ( $\mathrm{M} \mathrm{oL}$ primer) or $54^{\circ} \mathrm{C}$ ( $\mathrm{AOX} 1$ primer) for $1 \mathrm{~min}$, extension at $72^{\circ} \mathrm{C}$ for $1 \mathrm{~min}$. A final extension step at $72^{\circ} \mathrm{C}$ for 7 min was carried out in all cases. The controls for PCR were P. pastoris colonies lacking the additional MoL gene, and the PCR mixture without P. pastoris cell. Finally, the amplified products were separated by $1 \%$ agarose gel electrophoresis, and visualized.

The supernatant of GS115/pPIC 9/MoL colony 2 was concentrated 10 -fold, the resulting protein was quantified using a Qubit ${ }^{\circ}$ 2.0 Fluorometer (Invitrogen) and was purified using a Ni-NTA spin kit according to the manufacturer's instructions (Qiagen, USA). A $600 \mu \mathrm{L}$ aliquot of the concentrated $\mathrm{MoL}(\mathrm{pH} 7.5)$ was bound to the Ni-NTA spin column and eluted in buffer containing $500 \mathrm{mM}$ imidazole, $300 \mathrm{mM} \mathrm{N} \mathrm{aCl}, 200 \mathrm{mM} \mathrm{KCl}$, and 50 $\mathrm{mM}$ phosphate. The purity of $\mathrm{MoL}$ was verified by SDS-PAGE; $10 \mu \mathrm{L}$ of eluate containing the purified $\mathrm{MoL}$, flow through, and concentrated sample were mixed with $10 \mu \mathrm{L}$ of tricine-SDS loading buffer and loaded into an $18 \%$ SDS-PAGE (Bio-Rad, USA). The coagulation activity of the purified MoL was determined using a 
spectrophotometer as described previously, using turbid water of approximately 400 NTU ${ }^{13)}$.

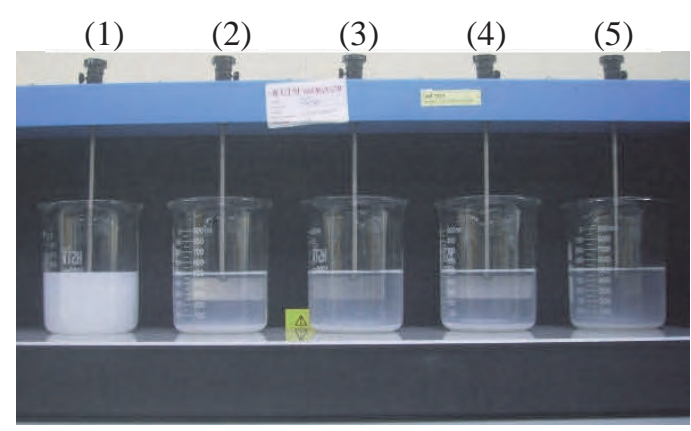

Fig. 1. J ar test for turbidity removal, using $500 \mathrm{~mL}$ of kaolin suspension (600 NTU) and $10 \mathrm{~mL}$ of GS115/pPIC 9/MoL supernatant. (1) no coagulant (control); (2) colony 2; (3) colony 29; (4) colony 31; (5) colony 49.

\section{R esults and Discussion}

\subsection{Coagulation performance of culture supernatants from 50 transformed $P$. pastoris colonies}

The cultured supernatants from transformed $P$. pastoris colonies contain native protein as well as recombinant $\mathrm{M} \mathrm{oL}$. Supernatant from colony 2 achieved a $96 \%$ reduction in turbidity, from 600 to $20 \mathrm{NTU}$, the highest of all the samples tested (Fig. 2). M oreover, the $\mathrm{MoL}$ in the $\mathrm{P}$. pastoris supernatants displayed coagulation activity that was similar to that of $M$. oleifera lectin extracted from seeds ${ }^{14}$ ). Over $80 \%$ of the cultured colonies expressed high concentrations of $\mathrm{MoL}$ in their supernatants, giving a significant reduction in kaolin suspension turbidity. The remaining colonies exhibited a less than $70 \%$ reduction in turbidity relative to the control, indicating lower levels of secreted $\mathrm{MoL}$. The lowest turbidity reduction was seen with colonies 5 , 7, 17, 46, and 47; no MoL and low native protein was secreted in their supernatants. In the present study, the integration of the PPIC9 plasmid into the genomes of the P. pastoris was confirmed by growing transformed colonies on selective regeneration dextrose (RD) agar. However, the RD agar screen only verifies the expression of the HIS4 in pPIC9, and it is possible that the MoL is not expressed, perhaps because of incomplete insertion or subsequent deletion.

In over $80 \%$ of colonies displaying efficient turbidity removal, variations can be attributed to the efficiency of MoL integration into the P. pastoris genome. Previously, the efficiency of heterologous protein expression improved significantly when multiple copies of the expression plasmid were integrated into host cells ${ }^{14)}$. The integration of multiple pPIC $9 / \mathrm{MoL}$ plasmids into the P. pastoris genome, through tandem insertions at the restriction enzyme Sall site within his4, was reported to substantially increase protein yield ${ }^{15)}$. The four colonies inducing the highest reduction in turbidity, colonies 2 , 29,31 , and 49, were selected for further analysis.
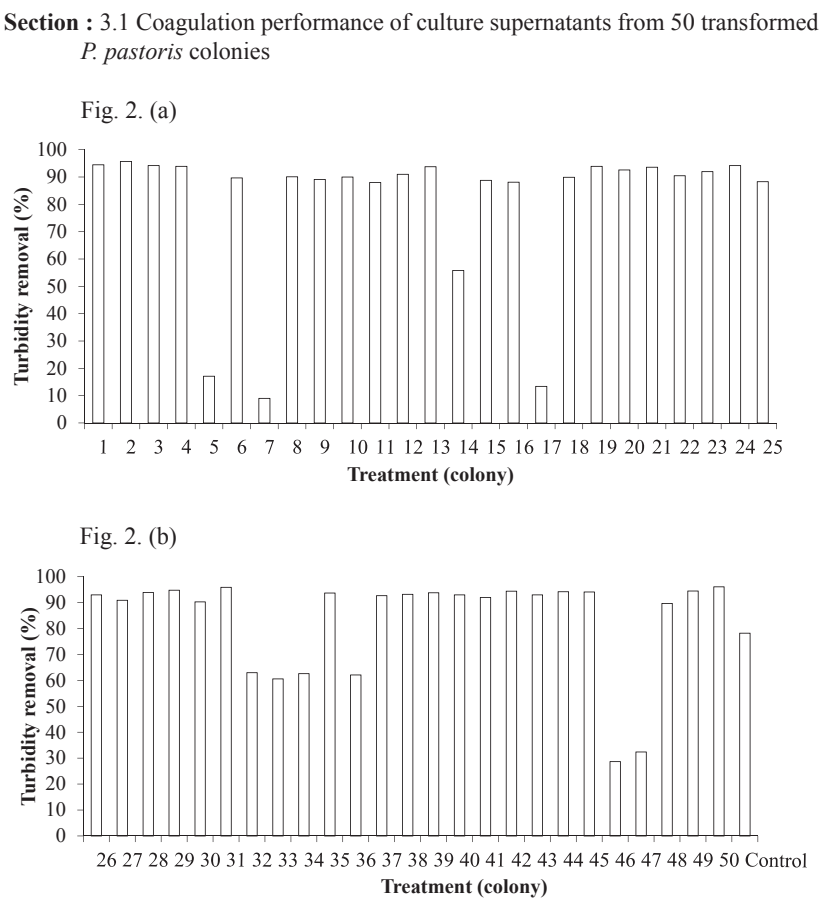

Fig. 2. Turbidity removal by cultured supernatant of transformed P. pastoris colonies and a control. A kaolin suspension was used at an initial turbidity of 600 NTU. (a) Results with supernatants from GS115/pPIC9/MoL colonies 1 through 25; (b) Results with supernatants from GS115/pPIC9/ MoL colonies 26 through 50 , as well as the GS115/his control.

The neutralization observed during turbidity removal may be attributable to the coagulant properties of $\mathrm{MoL}$, which has a net positive charge on its surface. The interaction of the positively charged $\mathrm{MOL}$ and the negatively charged kaolin is expected to form flocs, leading to coagulation ${ }^{16)}$. Natural coagulants extracted from organisms, such as the MoL used here, are viable alternatives to currently used coagulants, as they are known to be biodegradable and safe for human health. Additionally, they are effective flocculating agents for various colloidal suspensions, with a wide range of effective doses ${ }^{16)}$.

\subsection{Statistical analysis of the four supernatants with highest turbidity removal}

Turbidity removal was examined statistically, as follows. Triplicate samples of the four colonies that gave the highest levels of turbidity removal with the 600 NTU kaolin suspension were examined using a 200 NTU suspension, and compared with the control. The results confirm the highly effective removal of turbidity, indicating the presence of $\mathrm{MoL}$ in the respective supernatants (Table 1 ). 
The colony 2 supernatant achieved significantly higher turbidity removal than did the control $(42 \%)$, suggesting that $\mathrm{MoL}$ was produced at highest level compared to other three colonies (colony 29, 31 and 49). Overall, all four of the colony supernatants exhibited significantly higher turbidity removal than that of the control.

Table. 1. Statistical analysis of the difference in turbidity removal achieved by the control and colony supernatants, using an initial turbidity of 200 NTU.

\begin{tabular}{|c|c|c|c|}
\hline \multicolumn{2}{|c|}{ Supernatants } & \multirow{2}{*}{$\begin{array}{c}\begin{array}{c}\text { M ean } \\
\text { Difference }\end{array} \\
42.03^{*}\end{array}$} & \multirow{2}{*}{$\begin{array}{c}\text { Sig. }(P< \\
0.01) \\
0.001\end{array}$} \\
\hline 2 & & & \\
\hline 29 & Control & $41.28^{*}$ & 0.001 \\
\hline 31 & & $39.23^{*}$ & 0.002 \\
\hline 49 & & $40.13^{*}$ & 0.001 \\
\hline
\end{tabular}

* The mean difference is significant at $<0.01$ level.

\subsection{PCR analysis of G S115/pPIC 9/MoL colony 2}

The MoL gene inserted into the $P$. pastoris genome was investigated further using universal $A O X 1$ and specific MoL primers, respectively. As shown in Fig. 3, in lane 2, a clear 724 bp band was seen corresponding to $500 \mathrm{bp}$ of AOX1 fused to $224 \mathrm{bp}$ of MoL, indicating that $\mathrm{MOL}$ was properly inserted into the PPIC 9 plasmid. The presence of MoL within the $724 \mathrm{bp}$ amplicon was then confirmed using MoL-specific primers and the colony 2 genome as a template. The MoL-specific primers were designed to be complimentary to the 22 bp sequences at either end of the MoL sequence. As shown in Fig. 3, a $224 \mathrm{bp} \mathrm{MoL}$ band was seen as expected (lane 3), and no band was seen in the negative control lacking template DNA (lane 4). The observed molecular weight of $\mathrm{MOL}$ is consistent with the amplicon product of $\mathrm{MO}_{2.1}{ }^{17}$ ). The insertion of $\mathrm{M} \mathrm{OL}$ after $\mathrm{AOX} 1$ promoter could induce high levels of $M$ oL production.

Two different genes in the $P$. pastoris genome, $A 0 \times 1$ and $A O X 2$, are expressed when the carbon source is methanol. These genes are transcribed at different levels; AOX1, which possesses a strong promoter (PAOX1), generates the heterologous protein more efficiently than AOX2. The combination of PAOX1-mediated transcriptional activation and the secretion of recombinant proteins by $P$. pastoris is extremely useful, and impressive protein yields can be achieved (up to $22 \mathrm{~g} / \mathrm{L}$ of intracellular protein and $15 \mathrm{~g} / \mathrm{L}$ of secreted protein) ${ }^{18)}$.

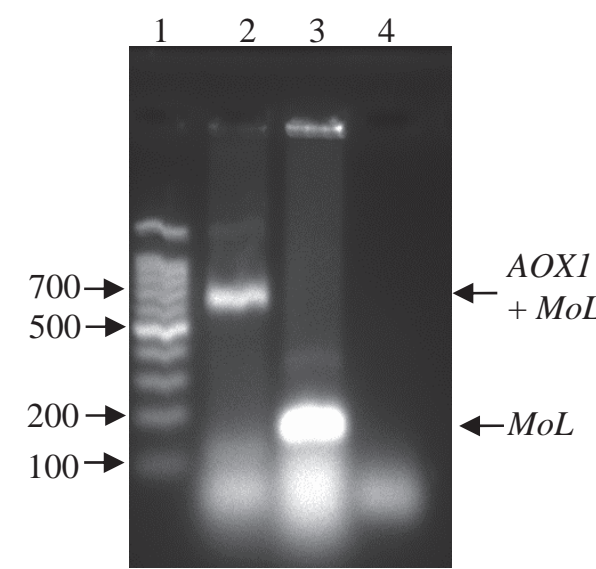

Fig 3. PCR analysis of GS115/pPIC9/M OL colony 2 . Lane 1: 100 bp DNA marker (Promega); lane 2: $P C R$ product amplified with AOX 1 primers (724 bp); lane 3: PCR product amplified with $\mathrm{MoL}$ primers; lane 4: negative control (no colony. The arrows on the left indicate molecular weight.

\subsection{SDS-PAGE evaluation of M oL secreted from $P$. pastoris}

The increased expression of heterologous $\mathrm{MoL}$ compared to that of the native $P$. pastoris protein was determined by SDS-PAGE, and a more intense $8 \mathrm{kDa}$ band was seen in the concentrated supernatant (Fig. 4, lane 3). Following protein purification, the presence of secreted $\mathrm{MoL}$ in the culture supernatant from GS115/pPIC9/MoL colony 2 was confirmed by SDS-PAGE, and a single $8 \mathrm{kD}$ a band was observed (Fig. 4, lane 1). However, this band was of a higher molecular weight than the previously reported $6.5 \mathrm{kDa}$ for $\mathrm{MoL}$, indicating that the protein has undergone post-translational modification. Glycosylation of $\mathrm{MoL}$ following extracellular secretion by P. pastoris increased its molecular weight by $\sim 1.5 \mathrm{kD}$ a, consistent with a study describing the production of the $40.3 \mathrm{kDa}$ recombinant Triticum aestivum xylanase inhibitor I (rTAXI-I) protein in P. pastoris, which showed a $1732 \mathrm{Da}$ increase in mass due to $\mathrm{N}$-glycosylation ${ }^{19)}$. L ike all eukaryotic organisms, but unlike bacterial expression systems, $P$. pastoris is able to perform glycosylation, although the glycosyl chains it generates are much shorter than those produced by S. cerevisiae ${ }^{20)}$. 


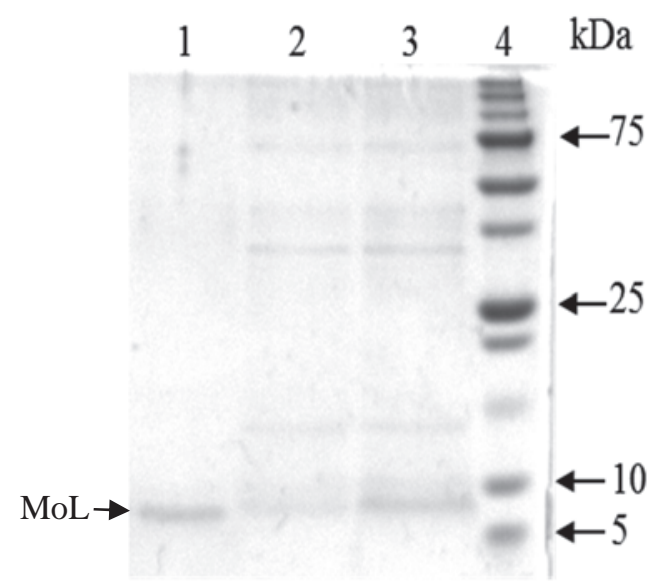

Fig. 4. SDS-PA GE using an $18 \%$ tricine buffer. Lane 1 : purified MoL (314 $\mu \mathrm{g} / \mathrm{mL})$; lane 2: sample flow-through; lane 3: concentrated supernatant from GS115/pPIC9/M oL colony 2; lane 4: precision plus protein dual extra markers (Bio-Rad). The arrows on the right indicate molecular weight.

\subsection{Coagulation test for purified M oL}

Turbidity removal was investigated at increasing concentrations of purified MoL. As shown in Fig. 5, the most effective purified MoL concentration was the lowest, $2 \mu \mathrm{g} / \mathrm{mL}$, which achieved $83 \%$ turbidity removal, with $4,6,8$, and $10 \mu \mathrm{g} / \mathrm{mL}$ of purified $\mathrm{MoL}$ being progressively less effective. However, at the highest protein concentration tested, $10 \mu \mathrm{g} / \mathrm{mL}$, the coagulant activity achieved by the purified MoL, defined as the percentage of turbidity removal, was still $13.86 \%$ better than that of the control. At MoL concentrations of 6 $\mu \mathrm{g} / \mathrm{mL}$ and above, there is an excess of MoL over suspended kaolin, and the occurrence of a charge reversal effect is possible. This is consistent with a previous report on the chemical coagulant aluminum, wherein the charge reversal effect began to dominate at higher concentrations due to the restabilization of negative particles ${ }^{21)}$.

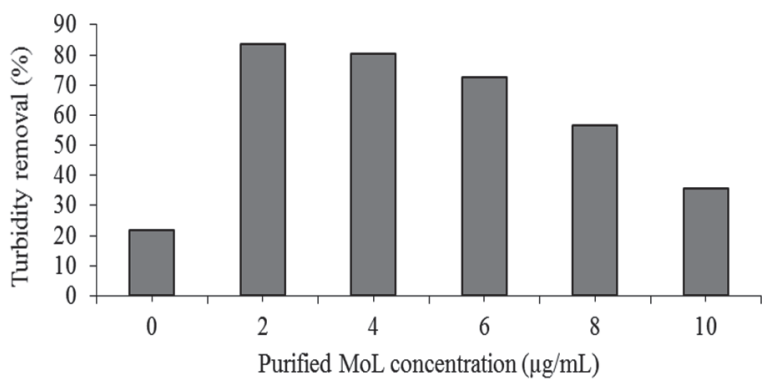

Fig. 5. Percentage turbidity removal by increasing concentrations of purified M oL.

\section{Conclusion}

M. oleifera seed extract contains an active coagulant protein. In methods using this seed extract to treat turbid water, the entire extract is mixed with either distilled water or salt water, and then added directly to turbid water to study the turbidity removal. Although some of the extraction methods previously used with M. oleifera seeds have been applied in this study, we have also shown that $P$. pastoris supernatant containing $\mathrm{MoL}$ is highly effective in reducing the turbidity of water, from 600 to 20 NTU.

Recombinant $\mathrm{MoL}$, produced by $\mathrm{P}$. pastoris, is a promising coagulant for water treatment. Molecular screening of the transformed colonies to identify those that are producing high levels of $\mathrm{M} \mathrm{OL}$ is very expensive, and so a direct screening using protein activity as an indicator of $\mathrm{MoL}$ expression has been described in this study. The highest level of MoL production, indicated by the reduction in turbidity, was seen with GS115/pPIC9/M oL colony 2.

Secreted MoL in colony supernatants was active in highly turbid waters of 600 and 200 NTU. The high turbidity removal activity was confirmed using purified MoL at 400 NTU kaolin suspension. However, in order to reduce the cost of water purification, the supernatant could be used directly in water treatment. The MoL-containing $P$. pastoris supernatant could also potentially be used to treat turbid water from reservoirs, with water quality being monitored thereafter. As a natural coagulant, we believe the sludge production from $\mathrm{MoL}$-containing supernatants will be much lower than that of conventional coagulants, and its storage in landfill much safer ${ }^{1)}$.

\section{Acknowledgments}

The authors gratefully acknowledge MJIIT, UTM, $K$ uala Lumpur as given me scholarship for three years and provide all facilities to do this research.

\section{References}

1) E.E.L. Muller, A.R. Sheik and P. Wilmes, Current O pinion in Biotechnology, 30, 9-16 (2014).

2) M.A. Oturan, and A. J ean-Jacques, A review, Environmental Science and Technology, 44, 2577-2641 (2014).

3) H. Xua, F. Xiaoa, D. Wanga and C. Y eb, Colloids and Surfaces A: Physicochem. Eng. Aspects, 456, 211-221 (2014).

4) M. Zainal-A bideen, A . A ris, F. Yusof, Z. A bdul-M ajid, A. Selamat and S.I. Omar, Water Science \& Technology, 65, 496-503 (2012). 
5) A.W.M. Azhar, H. Hara and M.N.M. Johari, Malaysian Journal of Civil Engineering, 28, 26-34 (2016).

6) J.R. Walton, Journal of Alzheimer's Disease, 765-838 (2014).

7) K.C. Valverde, L.C.K. M oraes, M.C. Bongiovani, F.P. Camacho and R. Bergamasco, Acta Scientiarum, 5, 485-489 (2013).

8) C.Y. Y in, Process Biochem., 45, 1437-1444 (2010).

9) G. M uthuraman and S. Sasikala, Journal of Industrial and Engineering Chemistry, 20, 1727-1731 (2014).

10) S.K. Kansal and A. Kumari, Chem. Rev., 114, 4993-5010 (2014).

11) A.F.S. Santos, L.A . Luz, A.C.C. A rgolo, J.A. Teixeira, P.M.G. Paiva and L.C.B.B. Coelho, Process Biochemistry, 44, 504-508 (2009).

12) Invitrogen, Life Technologies Corporation, (2014).

13) R.S. Ferreira, T.H. Napolea O, A.F.S. Santos, R.A. Sa, M.G. Carneiro-da-Cunha, M.M.C. Morais, R.A. Silva-Lucca, M.L.V. Oliva, L.C.B.B. Coelho, and P.M.G. Paiva, Lett. Appl. Microbiol., 53, 186-192 (2011).

14)S. Kelle, K. Zelena, U. Krings, D. Linke and R.G. Berger, Protein Expression and Purification, 95, 233-239 (2014).

15)R.M. Bill, Methods and Protocols, Methods in Molecular Biology, 866, Springer (2012).

16) B.S. Deshmukh, S.N . Pimpalkar, R.M . Rakhunde and V.A. Joshi, International Journal of Innovative Research in Science,Engineering and Technology, 2(11), 6183-6189 (2013).

17) A.R. Pavankumar, J. Noren, L. Singh and N.K.C. Gowda, RSC Adv., 4, 7136-7141 (2014).

18) T. Vogl and A. Glieder, New Biotechnology, 30 386-401 (2013).

19) K. Fierens, N. Geudens, , K. B rijs, C.M. Courtin, K. Gebruers, J.Robben, S.V. Campenhout, G. Volckaert and J.A. Delcour, Protein Expr. Purif., 37, 39-46 (2004).

20) S. M acauley-Patrick, M.L. Fazenda, B. M CN eil and L.M. H arvey, Yeast, $22,249-270$ (2005).

21)J. Duan and J. Gregory, Advances in Colloid and Interface Science, 100-102, 475-502 (2003). 